\title{
Sobrecrecimiento bacteriano intestinal en pacientes con pancreatitis crónica
}

\author{
Carla Mancilla A ${ }^{1}$, Ana María Madrid $\mathbf{S}^{1}$, \\ Carmen Hurtado $\mathrm{H}^{1}$, Carolina O rellana $\mathrm{B}^{\mathrm{a}}$, \\ Margarita Peña $Z^{a}$, Eduardo Tobar $A^{b}$, Zoltán Berger $\mathbf{F}^{1}$. \\ Small intestine bacterial overgrowth \\ in patients with chronic pancreatitis
}

\begin{abstract}
Background: Previous reports describe $30-40 \%$ of small intestine bacterial overgrowth (SIBO) in patients with chronic pancreatitis (CP), SIBO is a cause of persistent symptoms in this group of patients even when they are treated with pancreatic enzymes. Aim: To asses the frequency of SIBO in patients with CP. Patients and methods: We studied 14 patients with CP using an hydrogen breath test with lactulose to detect SIBO, a nonabsorbable carbohydrate, whose results are not influenced by the presence of exocrine insufficiency. Main symptoms and signs were bloating in 9 (64\%), recurrent abdominal pain in 8 (57\%), intermittent diarrhea in 5 (36\%) and steatorrhea in 5 (36\%). At the same time we studied a healthy control group paired by age and sex. Results: SIBO was present in 13 of 14 patients with CP $(92 \%)$ and in 1 of 14 controls $(\mathrm{p}<0.001)$. The only patient with CP and without SIBO was recently diagnosed and had minimal morphologic alterations in computed tomography and endoscopic pancreatography. Conclusions: SIBO is common in CP and may be responsible for persistent symptoms. Proper diagnosis and treatment could alleviate symptoms and improve quality of life (Rev Méd Chile 2008; 136: 976-80).
\end{abstract}

(Key words: Gastrointestinal contents; Malabsorption syndrome; Pancreatitis, chronic)

Recibido el 20 de junio, 2007. Aceptado el 16 de abril, 2008.

${ }^{1}$ Sección de Gastroenterología. Hospital Clínico Universidad de Chile. Santiago de Chile.

aAlumna de Medicina. Facultad de Medicina. Universidad de Chile

bMagíster en Epidemiología Clínica, Facultad de Medicina, Universidad de Chile

L a pancreatitis crónica (PC) es una inflamación crónica del páncreas, con destrucción progresiva del parénquima, que es reemplazado por fibrosis difusa o focal, acompañada por atrofia y pérdida de la diferenciación de células acinares, con o sin calcificaciones. Este sustrato anatómico

Correspondencia a: Dr. Zoltán Berger F. Hospital Clínico Universidad de Chile. Santos Dumont 999. Santiago Chile. E mail: zberger@terra.cl se refleja en la pérdida progresiva y secuencial de las funciones exocrina y endocrina de la glándula ${ }^{1}$.

La principal manifestación de la disfunción exocrina es la maldigestión que lleva a un déficit nutricional. Sin embargo, la pérdida de jugo pancreático y de su acción bactericida se asocia también a otra manifestación frecuente en estos pacientes que constituye el sobrecrecimiento bacteriano intestinal $(\mathrm{SBI})^{2,3}$.

La mayoría de las bacterias ingeridas por vía oral son destruidas por el pH ácido del estómago, 
por lo que a nivel del intestino delgado se observa una baja población bacteriana, con excepción del íleon terminal. La flora bacteriana incluye hasta $10^{3}$ unidades formadoras de colonias (UFC) en el estómago y no más de $10^{5}$ en duodeno y yeyuno. En el íleon distal hay normalmente un incremento de la concentración bacteriana, encontrándose aproximadamente $10^{7}-10^{8} \mathrm{UFC}$, mientras que en el colon existe un marcado aumento con $10^{10}$. $10^{11} \mathrm{UFC}^{4}$.

El SBI se define como un recuento bacteriano $>10^{5} \mathrm{UFC} / \mathrm{ml}$ en el intestino delgado proximal y se asocia a múltiples consecuencias como cuadros infecciosos secundarios a traslocación bacteriana, malabsorción de varios nutrientes y presencia de síntomas digestivos inespecíficos ${ }^{5}$.

Por otra parte, el metabolismo bacteriano de los carbohidratos produce ácidos, agua y gases, siendo los principales gases $\mathrm{H}_{2}$ y $\mathrm{CO}_{2}$. El CO proviene del metabolismo de todas las células, mientras que solamente las bacterias son capaces de producir $\mathrm{H}_{2}$.

En el SBI se puede demostrar un incremento en la producción de $\mathrm{H}_{2}$, secundario a la sobrepoblación bacteriana, mediante la medición de hidrógeno en aire espirado (Breath Test) luego de la ingestión de un carbohidrato no digerible (lactulosa). El Breath Test es actualmente el método no invasivo aceptado para el diagnóstico de SBI.

Existen pocos trabajos que hablan del SBI en pacientes con PC. De ellos, Trespi describe $34 \%$ de SBI en pacientes con PC y Lembcke $40 \%$, estudiados con $\mathrm{H}_{2}$ espirado con glucosa y ${ }^{14} \mathrm{C}$ colilglicina respectivamente ${ }^{2,3}$.

El objetivo de este estudio fue establecer la frecuencia de SBI en pacientes con pancreatitis crónica mediante estudio de $\mathrm{H}_{2}$ en aire espirado con lactulosa. Se eligió como substrato la lactulosa por tratarse de un carbohidrato no digerible, cuyo resultado es independiente de la función exocrina del páncreas.

\section{PACIENTES Y MÉTODO}

Se ingresó al estudio a 14 pacientes con PC controlados en el Servicio de Gastroenterología con diagnóstico establecido por cuadro clínico y pancreatografía retrógrada y
14 sujetos sanos pareados por edad y sexo como grupo control. Los pacientes firmaron consentimiento informado y el proyecto fue autorizado por el Comité de Ética del Hospital Clínico de la Universidad de Chile.

Cada paciente contestó una encuesta para evaluar síntomas como distensión abdominal, dolor abdominal recurrente, esteatorrea y diarrea intermitente.

Para el estudio de SBI se realizó el test de $\mathrm{H}_{2}$ en aire espirado. Los pacientes consumieron una dieta pobre en fibras los días previos al examen. Se utilizaron colutorios de clorhexidina antes del inicio del test para evitar resultados falsos positivos debidos a la flora oral. La recolección de las muestras de aire espirado se realizó desde la boca del paciente cada 10 minutos por 180 minutos antes y después de la ingesta de $25 \mathrm{~g}$ de lactulosa. Las muestras fueron analizadas en un cromatógrafo de gases (QuinTron MicroLyzer, USA) y los resultados se expresan en partes por millón (ppm). Se consideró SBI la presencia de un hidrógeno espirado basal $>20 \mathrm{ppm}$ o 2 cifras superiores a $20 \mathrm{ppm}$ en los primeros $60 \mathrm{~min}^{6}$.

Además, en 12 pacientes se realizó la determinación de los niveles de elastasa-1 fecal como

\section{Tabla 1. C aracterísticas demográficas de 14 pacientes con PC}

\begin{tabular}{|lcccl|}
\hline Paciente Sexo & $\begin{array}{c}\text { Edad } \\
\text { (años) }\end{array}$ & $\begin{array}{c}\text { Tiempo } \\
\text { evolución } \\
\text { (años) }\end{array}$ & $\begin{array}{l}\text { Etiología } \\
\text { PC }\end{array}$ \\
\hline 1 & M & 50 & 25 & Alcohol \\
2 & M & 26 & 4 & Idiopática \\
3 & M & 33 & 8 & Alcohol \\
4 & M & 21 & 2 & Idiopática \\
5 & M & 64 & 10 & Alcohol \\
6 & F & 38 & 9 & Idiopática \\
7 & M & 64 & 11 & Alcohol \\
8 & M & 57 & 2 & Autoinmune \\
9 & F & 59 & 14 & Idiopática \\
10 & M & 40 & 12 & Alcohol \\
11 & M & 62 & 7 & Alcohol \\
12 & M & 56 & 4 & Autoinmune \\
13 & M & 62 & 30 & Alcohol \\
14 & F & 56 & 1 & Autoinmune \\
\hline
\end{tabular}




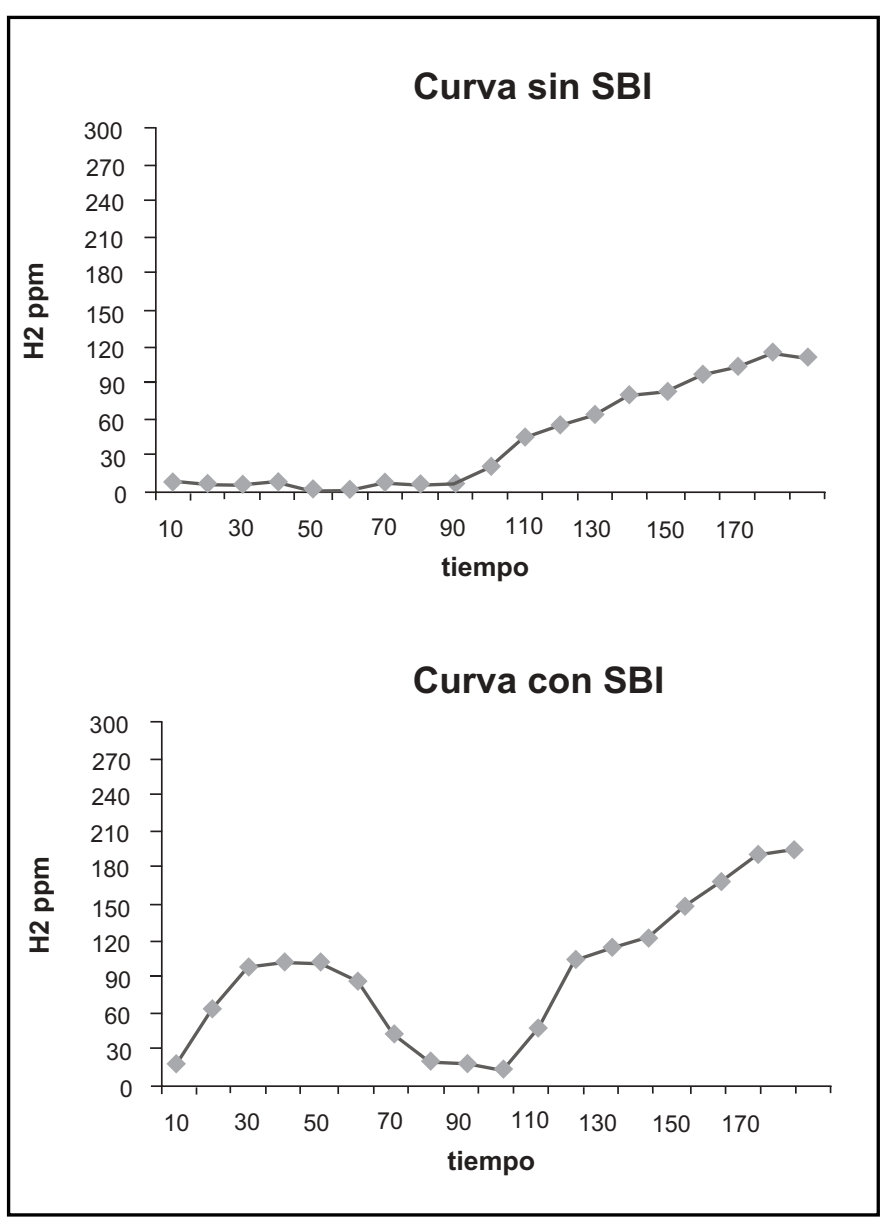

Figura 1. Curvas de $\mathrm{H}_{2}$ en aire espirado sin SBI (control) y con $\mathrm{SBI}$ (paciente con PC).

reflejo de la función exocrina del páncreas. La determinación de la elastasa-1 en deposiciones se realizó mediante técnica de Elisa (Schebo Biotech, Giessen, Alemania), siendo el valor normal mayor a $200 \mu \mathrm{g} / \mathrm{g}$ de deposición. Valores entre 100-200 $\mu \mathrm{g} / \mathrm{g}$ representan insuficiencia pancreática exocrina moderada y menores de $100 \mu \mathrm{g} / \mathrm{g}$, severa.

Se hizo análisis descriptivo y estadístico mediante test exacto de Fisher ( $p<0,001$ ).

\section{Resultados}

Se estudiaron 14 pacientes con diagnóstico de PC, 11 hombres y 3 mujeres. La edad promedio fue de
$49,1 \pm 14,7$ años. El tiempo promedio de evolución desde el diagnóstico fue de $9,9 \pm 8,5$ años. Las características demográficas de los pacientes se presentan en la Tabla 1.

La edad promedio de los controles (11 hombres y 3 mujeres) fue de 49,7 \pm 14,9 años.

La encuesta de síntomas gastrointestinales demostró: distensión abdominal en 9 (64\%), dolor abdominal recurrente en $8(57 \%)$, diarrea intermitente en 5 (36\%) y esteatorrea en 5 (36\%) de los pacientes portadores de PC. En 10 de los 12 pacientes en que se realizó la determinación de elastasa-1 fecal, se encontró un nivel menor de $100 \mu \mathrm{g} / \mathrm{g}$ de deposición, reflejo de una severa insuficiencia exocrina y en los otros dos el valor fue menor de $200 \mu \mathrm{g} / \mathrm{g}$ (insuficiencia moderada) ${ }^{7}$.

Cuatro pacientes eran diabéticos y 9 se encontraban en tratamiento con enzimas pancreáticas. Nueve pacientes presentaban calcificaciones pancreáticas en la tomografía.

Los tres pacientes con diagnóstico de pancreatitis autoinmune habían sido sometidos a resección pancreática con confirmación histológica del diagnóstico.

El resultado del test de $\mathrm{H}_{2}$ en aire espirado con lactulosa fue compatible con SBI en 13 de 14 (92\%) pacientes con PC versus 1 de $14(8 \%)$ controles sanos ( $p$ $\varangle 0,001$ ) (Figura 1). El único paciente con PC que no presentó SBI fue un paciente recién diagnosticado y con alteraciones morfológicas iniciales en la tomografía y pancreatografía endoscópica.

\section{Discusión}

Si bien la PC es considerada una enfermedad rara en Chile, es probable que esté subdiagnosticada, por encontrarse estos pacientes "ocultos" entre pacientes diabéticos y otros con diagnóstico de pancreatitis aguda o cáncer de páncreas ${ }^{8,9}$. La mayoría de los pacientes con confirmación de su diagnóstico están en tratamiento con enzimas pancreáticas, a pesar de lo cual se mantienen con 
síntomas digestivos principalmente distensión, dolor y diarrea. Estos síntomas, aunque inespecíficos, en presencia de condiciones predisponentes, pueden ser sugerentes de $\mathrm{SBI}^{10}$, de la misma forma en que se ha encontrado una prevalencia mayor a $70 \%$ de SBI en diversos trastornos digestivos funcionales ${ }^{11}$.

La confirmación del SBI es difícil. El estudio bacteriológico del contenido intestinal es un método invasivo con grandes limitaciones en cuanto a su rendimiento. El método no invasivo ampliamente utilizado y aceptado en el diagnóstico del SBI es el test de hidrógeno espirado con glucosa o lactulosa ${ }^{12,13}$. Sin embargo, los valores de sensibilidad y especificidad comunicados en la literatura para este método son cuestionables por la falta de un real gold standard, por lo que en nuestro trabajo los esfuerzos estuvieron centrados en evitar resultados falsos positivos y en comparar los hallazgos con un grupo control adecuado 14 . En modelo animal, Rubinstein et al demostraron la actividad bactericida del jugo pancreático ${ }^{15}$. Este fue bactericida frente a cepas de E. Coli, Klebsiella, Salmonella y Shigella y bacteriostático frente a Estafilococo, Pseudomona y Cándida. La actividad bactericida fue dependiente del $\mathrm{pH}$ alcalino y persistente a pesar del bloqueo enzimático.

De este modo, la disminución de la secreción pancreática presente en la PC puede favorecer la sobreproliferación bacteriana del intestino. En efecto, Casellas et al encontraron en un grupo de 15 pacientes con PC evidencias de SBI en 6 de ellos, mediante estudio de $\mathrm{H}_{2}$ espirado con glucosa, en estrecha relación con una marcada disminución de la secreción basal y estimulada de tripsina ${ }^{16}$. También se ha descrito una prolongación del tiempo de tránsito orocecal en pacientes con PC como causa de SBI ${ }^{17}$.

En la experiencia de Trespi en un grupo de 12 pacientes con PC y SBI tratados con enzimas pancreáticas, el tratamiento antibiótico de amplio espectro durante tres meses fue seguido de una

\section{REFERENCIAS}

1. Steer M, Waxman I, Freedman S. Chronic Pancreatitis. N Engl J Med 1995; 332: 1482-90.

2. TRESPI E, FERRIERI A. Intestinal bacterial overgrowth during chronic pancreatitis. Curr Med Res Opin 1999; 15: 47-52. normalización del test de $\mathrm{H}_{2}$ espirado y de remisión de la diarrea en 8 de ellos ${ }^{2}$. En nuestra experiencia, al igual que en otros grupos de estudio, encontramos un alto número de pacientes con sintomatología gastrointestinal generalmente moderada, a pesar de un adecuado tratamiento con enzimas pancreáticas. Parte de estos síntomas puede estar relacionada con SBI que se encontró en un porcentaje aun mucho mayor de pacientes con PC (92,8\%) que lo descrito previamente. La frecuencia de SBI en PC varía entre 30 a $50 \%$ en la literatura ${ }^{2,3,16,17}$. Sólo un trabajo es la excepción: Madsen et al no encontraron SBI en ninguno de sus pacientes en Dinamarca $^{18}$. Nuestro resultado es el otro extremo, ya que 13 de nuestros 14 pacientes presentaron elevado nivel de $\mathrm{H}_{2}$ en el aire espirado, compatible con SBI. No podemos explicar esta diferencia con razones técnicas: la dieta previa y la desinfección oral disminuyen la posibilidad de resultados falsos positivos y la diferencia comparando con un solo caso positivo entre los 14 controles sanos pareados es muy significativa.

Otra explicación posible para el elevado porcentaje de SBI en nuestros pacientes sería el consumo de alcohol, sin embargo el alcohol fue la etiología sólo en 7 de 14 pacientes y todos los pacientes se encontraban abstinentes por más de 1 año. La presencia de SBI es tan elevada en este grupo de enfermos que no parece relacionarse con la etiología del daño pancreático ni con la presencia de calcificaciones en la tomografía.

En conclusión, el SBI es una complicación muy frecuente en pacientes con PC avanzada de diversas etiologías. Su presencia se asocia a la persistencia de síntomas digestivos inespecíficos principalmente distensión, dolor y diarrea, a pesar del tratamiento de la insuficiencia exocrina. El diagnóstico oportuno y tratamiento antibiótico del SBI en PC es de importancia clínica puesto que podría disminuir las molestias de los pacientes y mejorar su calidad de vida.

3. Lembcke B, Kraus B, Lankisch PG. Small intestinal function in chronic relapsing pancreatitis. Hepatogastroenterology 1985; 32: 149-51.

4. Simon GL, Gorvach SL. The human intestinal microflora. Dig Dis Sci 1986; 31: 147-62.

5. TOSKEs PP. Bacterial overgrowth of the gastrointestinal tract. Adv Int Med 1993; 38: 387-407. 
6. Hamilton L. Methodological problems and accuracy of $\mathrm{H}_{2}$ breath test. In: Clinical application of breath test in gastroenterology and hepatology. Eds: Perri F., Andriulli A, International University Press 1998, Roma, pp 127-32.

7. Loser C, MOLgaard A, FöLsch UR. Faecal elastase 1: a novel, highly sensitive and specific tubeless pancreatic function test. Gut 1996; 39: 580-6.

8. Mancilla C, Planzer M, Berger Z. Pancreatitis Crónica ¿enfermedad rara o subdiagnosticada? Revista Hospital Clínico Universidad de Chile 2002; 13: 258-68.

9. Mancilia AC, Hurtado HC, Tobar AE, Orellana NI, Pineda BP, Castillo MI, Ledezma RR, Berger FZ. Función pancreática exocrina en diabetes mellitus: Determinación de elastasa fecal. Rev Méd Chile 2006; 134: 407-14.

10. Quera PR, Quigley EM, Madrid AM. Sobrecrecimiento bacteriano intestinal. Rev Méd Chile 2005; 133: 1361-70.

11. Madrid AM, Defilippi CC, Defilippi GC, Slimming AJ, QuERA PR. [Small intestinal bacterial overgrowth in patients with functional gastrointestinal diseases]. Rev Méd Chile 2007 Oct; 135: 1245-52.
12. KeRLiN P, Wong L Breath Hydrogen testing in bacterial overgrowth of the small intestine. Gastroenterology 1988; 95: 982-8.

13. SAad Rand Chey W. Breath tests for gastrointestinal disease: The real deal or just a lot of hot air? Gastroenterology 2007; 133: 1763-6.

14. SimRÉn M, StotZer PO. Use and abuse of hydrogen breath tests. Gut 2006; 55: 297-303.

15. Rubinstein E, Mark Z, Haspel J, Gur B, Dreznik Z, Mirelman D, TADMor A. Antibacterial activity of the pancreatic fluid. Gastroenterology 1985; 88: 927-32.

16. Caseluas F, Guarner L, Vaquero E, Antolín M, DE Gracia X, Malagelada J. Hydrogen breath test with glucose in exocrine pancreatic insufficieny. Pancreas 1998; 16: 481-6.

17. NordgaArd I, Rumessen JJ, Gudman-Hoyer E. Assimilation of wheat starch in patients with chronic pancreatitis. Positive effect of enzyme replacement. Scand J Gastroenterol 1992; 27: 412-6.

18. Madsen JL, Graff J, Philipsen EK, Scharff O, Rumessen JJ. Bile acid malabsorption or disturbed intestinal permeability in patients treated with enzyme substitution for exocrine pancreatic insufficiency is not caused by bacterial overgrowth. Pancreas 2003; 26: 130-3. 